\title{
Research on the Professional Construction Path of Engineering Cost of Transportation and Civil Engineering in Undergraduate Colleges under the Background of Big Data
}

\author{
Shoukui $\mathrm{He}^{1, \mathrm{a}}$, Yugang $\mathrm{Jian}^{2, \mathrm{~b}}$ and Yonggang Yan ${ }^{1, \mathrm{c}}$ \\ ${ }^{1}$ School of Economics and Management, Chongqing Jiaotong University, Chongqing 400074 \\ ${ }^{2}$ Department of Management, Chongqing Institute of Engineering, Chongqing 400056 \\ ahsk0657@cqjtu.edu.cn, b411078251@qq.com, 'cquyy2001@163.com
}

Keywords: Engineering cost; Building information modeling; Professional construction; Talent training Mode; Reform in teaching methods

\begin{abstract}
Internet + and big data model is revolutionizing the construction industry, making engineering cost management connect to the marketing rapidly. By contrast, education of engineering cost seems will derailment with the market. This paper analyzes the problems of engineering cost major's talent training under the background of big data. Combining with professional construction goal, it discussed the engineering cost major training mode architecture of transportation and Civil College, the engineering cost informationization supporting the research educational reform content, the curriculum perfection, establishing the modern teaching method reform path which adapts to the engineering cost informationization, exploring the innovative talent training mode, construction of the practice teaching construction and BIM engineering cost informationization experiment base construction and other professional construction path. And then analyzed the expected effect.
\end{abstract}

\section{大数据背景下交通土建本科院校工程造价专业建设 路径探讨}

\author{
何寿奎 ${ }^{1, a}$ ，简玉刚 ${ }^{2, b}$, 晏永刚 ${ }^{1, c}$ \\ 1. 重庆交通大学 经济与管理学院 中国 重庆 400074 \\ 2. 重庆工程学院 中国 重庆 400056 \\ ahsk0657@cqjtu.edu.cn, ${ }^{\text {b } 411078251 @ q q . c o m, ~}{ }^{c}$ cquyy2001@163.com
}

摘要: 互联网 + 与大数据模式正在革新建设行业, 工程造价管理快速接轨市场, 相比之下, 工 程造价教育仿佛正在脱轨市场。本文分析大数据背景下工程造价专业人才培养存在的问题, 结 合专业建设目标, 就交通土建院校工程造价专业人才培养模式架构、工程造价信息化配套教研 教改内容举措、完善课程设置、建立适应造价信息化的现代化教学方法改革路径、探索创新人 才培养方式、实践教学环节建设、BIM 工程造价信息化实验实训基地建设等专业建设路径进 行探讨, 并分析预期效果。

关键词: 工程造价；BIM 技术；专业建设；人才培养模式；教学方法改革

\section{1. 前言}

交通土建工程造价专业人才培养面临良好的发展机遇，也面临大数据时代市场适应性挑战。一 方面轨道交通建设快速发展、公路建设与高等级公路养护发展需要大量工程造价专业人才, 交 通土建院校工程造价专业人才培养及专业发展定位与一般建筑类工程造价专业人才培养有一 
定差异。另一方面, 工程造价专业为了适应大数据管理与 BIM(Building Information Modeling) 技术发展的需要, 专业教学面临教学手段、教学模式的重大变革。交通土建工程造价专业发展 定位: 在培养中牢牢抓住土木工程背景下道路桥梁技术基础, 瞄准造价管理技术学科前沿及大 数据环境下造价管理信息化技术发展方向，具有工程结构、工程测量、建筑施工、项目管理、 工程经济、组织行为学、工程造价信息等多学科交叉知识, 注重提升工程造价管理与工程咨询 领域的高级管理人才的工程实践能力及管理决策能力, 用螺旋式跃升发展手段努力实现工程造 价专业实现创新人才培养目标, 依托土木工程学科优势, 办出以交通土木建筑为基础和特色的 具有造价管理技术与工程咨询能力的工程造价专业, 培养出具有高素质、强能力, 有着浓厚的 交通特色，适应 BIM 工程造价管理信息化需要的应用复合型工程造价管理人才。

\section{2. 大数据模式下交通土建本科院校工程造价专业人才培养存在的问题}

目前, 随着大数据解决方案的落地, 工程造价行业建立了综合数据交互平台, 以形成完善的工 程项目管理、动态配价机制和按需定制解决方案。这意味着造价信息的个体跟踪和宏观应用实 现, 工程造价加速与市场接轨, 同时工程造价 BIM 化的条件成熟。随着 BIM 的落地, 建筑信 息可视化实现，现在的算量工作、算量软件都会被淘汰，相应的套价工作和计价软件也会升级。 传统工程造价专业教育下的造价工具、造价模式与现实需求的差距扩大。

(1) 面向 “大交通和大土木” 及大数据背景的工程造价综合计量及计价能力体系尚未完全形 成。长期以来, 交通土建院校工程造价专业的课程设置和教学内容较为偏向路桥工程板块, 房 屋建筑和市政公用工程板块的造价计量及计价的教学内容相对偏少, 学生难以做到土木建筑工 程造价和交通市政工程造价的融会贯通，教学内容上仍然停留在 “算量+套价” 的理论阐述， 导致学生毕业之后难以适应新形势下面向 “大交通和大土木” 及大数据背景下工程造价计量 及计价管理方式变革的要求。

(2)工程造价专业平台专课程之间的逻辑衔接性欠佳, 造价专业部分主干课程的教学内容存在 一定的重叠。一是工程造价专业的课程设置单纯地采用 “工程技术+管理+经济+法律” 的教学 模式, 各个板块之间的课程未能做到有效交叉和灵活结合, 专业基础课程、专业主干课程及专 业方向课程之间的逻辑衔接效果欠佳; 二是部分专业课程的教学内容存在一定的重叠, 例如施 工组织学与项目管理、工程经济学与项目评估、路桥施工技术与机械化施工等课程之间存在重 叠现象。

(3) 工程造价专业传统教学模式重理论、轻实践, 实习实践工作量及信息管理技术相对不足。 具体体现在: 一是目前我校工程造价本科专业大多主干专业课程的教学模式主要还是以教师课 堂教学为主, 相对于高职院校工程造价普通本科专业理论教学环节所占课时比例相对偏高; 二 是生产实习、毕业实习、课程设计、毕业设计等实践性教学环节的时间较短, 设计内容较为单 一, 大多停留在理论层面的计算书, 与工程实践存在一定的脱节, 对培养学生未来实际工作能 力的效果欠佳; 三是工程造价专业学生的实际动手操作能力较为偏弱, 部分工程造价专业毕业 生在大四阶段甚至毕业之后的一段时间还不能完全熟练地操作使用工程造价软件, 从而出现工 程造价专业本科毕业生职业适应能力差、职业适应期长等突出问题。

(4) 工程造价专业师资严重短期, 亟待打造一支数量充足、结构合理、专兼结合、造价编制与 信息管理融合的高素质工程造价专业教学团队。一是近年来随着工程造价本专科专业招生规模 的逐年扩增, 特别是高职院校工程造价专业的生师比也逐年扩大, 不少高校生师比达到超过 $30: 1$; 二是工程造价教学团队的年龄结构、专业结构、学历结构及职称结构仍有待优化, 尤其 是亟待补充一批年富力强的 “懂技术与管理、精计量及计价” 的管理科学与工程专业博士、注 册造价工程师、高级工程师充实师资力量和优化师资结构。

(5) 教学改革与质量工程方面: (1)传统实习方式亟待改进。工程造价专业学生毕业实习方式单 一, 效果不理想。原因是学生人数多, 施工单位出于安全因素不愿接收学生固定到工地实习; (2)课程设计组织与管理需要改进。部分课程教师组织课程设计的积极性不高, 原因学生人数多, 课程设计组织、管理与成绩评定比较困难; (3)毕业设计内容单一, 缺乏创新性。工程造价毕业 
设计题目多为施工组织设计与清单报价, 设计内容基本上是模块化标准化成果, 成果区分度不 高, 特色不鲜明, 不利于对学生创新能力培养。(4)工程造价教学研究研究论文数量少, 省部教 学研究成果获奖数量少; (5)缺乏国家级质量工程项目。

\section{3. 大数据背景下交通土建院校工程造价专业建设思路}

以卓越造价工程师培养为目标, 将创新性工程造价人才培养、高质量师资队伍建设、高水平教 育改革成果为任务, 探索工程造价专业建设思路, 积极推进工程造价专业发展。

(1) 以 “知识融合” 为核心理念, 以 “学科交叉” 为重要载体, 强化 “大土木”、“大交通”、 “大数据” 背景下工程造价专业的技术优势, 凸显工程造价平台课程的知识融合, 注重校企合 作模式和卓越工程师计划在工程造价专业建设及发展中的有效运用, 强调对工程造价专业学生 系统、全面、可持续的专业能力培养, 这不仅有利于促使造价专业学生具备就业初期的必备职 业能力, 而且亦又有助于确保学生在未来的工程职业生涯中拥有较强的适应大数据及工程造价 信息化执业发展潜力和专业竞争优势。

(2) 构建 “工程识图一BIM 算量一工程计价一造价标准-信息管理” 分层次、递进式人才培养 模式的专业建设思路。根据工程造价学科内涵和人才需求的特点, 遵循 “以技术为先导、以管 理为主体、技术与管理并重” 的专业建设理念、构建 “工程识图一BIM 算量一工程计价一造 价编制-信息管理” 分层次递进式的人才培养模式, 促使工程造价专业教育教学实现全面覆盖、 重点突出、理论与实践有机融合的整体目标。

(3) 结合 “一带一路” 发展需求, 持续提升人才培养的国际化素养和工程能力。“一带一路” 战略的逐步建立和实施, 势必要求各高校基于国际化、全球化的视野培养工程造价人才, 提升 工程造价专业学生的国际化素养和工程能力, 强调培养学生在国际工程造价计价及造价管理层 面的专业知识和能力素养。在工程造价专业未来教学环节中, 融入国际工程造价管理惯例及发 展前沿的知识, 从而提高学生的国际化素养和国际竞争意识。在工程造价人才培养方案设置、 课程理论教学和实践教学等层面要及时融入 “工程化” 思维; 鼓励教学系教师积极参加国内外 进修与学术交流, 提升科研能力与学术水平。

(4) 积极引入大数据与 BIM 工程造价信息技术等先进的教学理念和教学手段。在本专业建设及 发展过程中, 充分依托工程管理系工程模拟专业实验室和视频实验室的平台资源, 主动与国内 外工程造价软件研发机构展开深度合作, 将前沿性专业化信息技术 (互联网交流) 引入到教学 过程中。采用建筑信息模型 (BIM)、增强现实人机交互技术 (AR)、移动终端电子书 (IBOOK) 等前沿性信息化技术手段, 以 BIM 模型和可视化技术为载体有效串联各门独立核心课程, 对 工程项目尝试 “实景模拟和情景重现”, 以有效解决工程实时融入到课堂教学的技术瓶颈, 进 而对工程造价传统教学方式进行改革和创新, 从而实现 “多课程、同平台” 的互联互通和可视 化教学。

(5)注重校企合作、强化社会网络, 树立 “政产学研” 一体化的专业建设思路, 重视学生创新 创业能力的培养, 使学生更好地适应社会需求。一是联合建设集团公司、工程造价管理站等单 位展开深度合作。二是结合目前正在建设大型交通建设项目作为工程造价专业教学科研的实践 基地, 实现工程服务、课堂教学、科学研究和国际合作的相互促进和相互融合, 教学科研达到 “政产学研”一体化的集成发展, 培养学生的创新创业能力发展目标。

\section{4. 大数据背景下交通土建工程造价本科专业建设路径}

4.1. 人才培养模式架构

4.1.1 探索用学科设计竞赛、BIM 建模与算量竞赛、科技活动培养创新型人才培养模式。

以学生课外科技创新活动为动力, 用有价值的科研项目激发学生参与科研及实践的热情, 通过 BIM 建模与算量竞赛、各类科技竞赛激发学生创新意识、培养学生专长, 锻炼学生分析问题、 解决问题和综合运用所学知识的能力和技巧。利用科研资源加强学生创新活动平台建设。提出 “感知 $\rightarrow$ 学习 $\rightarrow$ 实践 $\rightarrow$ 创新” 四位一体的教学理念, 建立以科研促教学、强化平台建设、加强 
课外科技活动管理与指导的长效机制, 分层次、有重点地建设普及性和专题性的实践与科技活 动平台活动。

建立学生课外科技兴趣活动的可持续发展模式。(1)借鉴国外 (韩、美、日等) 成功的教研模式, 学生根据自己的兴趣爱好结合专业方向, 成立多个兴趣活动小组, 每个小组 3-5人; (2)对学生 的课外科技活动给予专向经费进行资助, 要求做好科技活动项目内容的继承性、积累性工作, 使后续学生的工作开展更容易上手和创新出成绩; (3)对兴趣活动小组工作进行积累和提炼, 用 做教学的生动案例, 实现教学相长; (4)以学生身边同学的业绩来启发学生的热情和兴趣, 达到 提高专业整体水平的目的。

4.1.2 探索人才培养与生产实践、工程项目及信息化管理相结合的新模式。

(1) 提供一套模拟企业实际的培训计划, 让学生透过多样化、生产或工作流程获取不同层次的 企业和科技知识, 使学生获得处理企业实际问题的经验, 提高学生综合运用所学知识的能力;

(2) 在现有的实验平台基础上创建独立的工程造价专业实验室，围绕专业核心课程开发设置多 层次的设计性、综合性、创新性的实验平台, 培养学生分析问题、解决问题的能力和技巧;

分层次、有重点、创特色地开展普及性和专题性的企业实践、BIM 建模与算量竞赛与科技创 新活动, 营造企业实践与科技创新氛围, 打造创新团队, 点面结合, 从广度和深度提升学生企 业实践与科技创新的能力。

4.1.3 搭建交通土建工程造价专业 “校企合作, 产教互促” 的人才培养模式。

一是通过搭建校企合作平台, 为学生提供实习实践机会, 使学生在校期间就可以获得准工程师 训练; 二是由工程造价咨询企业和校内教师联合开展工程造价实践性教学环节的指导 (例如安 排校内教师和校外造价工程师联合指导本科毕业实习和毕业设计), 从而实现产教融合、产教 互促。

4.1.4 探索工程造价专业的订单式人才培养模式。

以国家骨干企业用人单位的需求为导向, 以产学研合作为纽带, 与中国大型建筑企业集团和工 程咨询公司合作探索订单式培养国际工程造价咨询专门型人才的订单式培养模式, 以有效化解 用人单位造价专业人才紧缺和高校造价学生就业择业之间的矛盾。

以参加广联达市政工程算量软件、BIM 应用软件等主流工程造价软件应用大赛为载体, 构建 “以赛促学, 以赛促教, 赛教结合” 的培养模式。

通过对接国内知名工程造价软件研发企业、中国建设工程造价管理协会, 中国建设教育协会, 鼓励学生参加全国广联达算量大赛和斯维尔 BIM 造价软件应用竞赛, 强化工程造价专业学生 的实践操作技能, 以提升学生的动作操作能力和管理创新能力。

4.1.5 构建 “验证型、设计型、综合型、创新型” 逐层递进的工程造价实验教学内容体系。 主要包括公路工程造价编制、建筑装修工程造价编制、项目管理沙盘、模拟招标、施工方案设 计竞赛、未来工程师技能大赛与项目管理论坛等实践教学与训练, 以完善和优化现有工程造价 实验教学内容体系。

4.2. 适应大数据与造价管理信息化的配套教研教改内容举措

(1) 构建工程造价校级 “工学融合工作室”。“工学融合工作室” 是以具体工程项目为载体, 从造价基础理论一清单定额规则一BIM 建模与算量一工程项目计价一成果生成一成果审核, 均围绕项目导向、任务驱动进行过程学习与体验, 真正做到 “工学融合, 教学做合一”。

(2) 持续优化现有工程造价专业平台课程和方向课程。结合现行全国造价员、注册造价工程执 业资格考试、BIM 建模与算量的能力要求, 整合现有核心专业课程教学内容, 进行课程改革 与创新, 增加信息技术与 BIM 建模与算量理论与实践课程, 实现理论和工程实践有机融合。

(3) 组织编著具有交通行业特色的工程造价系列教材及执业资格考试辅导资料。基于 “懂技术、 精计量、擅计价、会管理” 专业建设目标, 结合工程造价专业教师在工程造价咨询领域及全国 造价员、注册造价工程师培训层面的丰富经历, 组织编著具有交通行业特色的工程造价系列教 材, 以及编写住建部造价工程师、交通部甲级造价师等注册执业资格考试辅导培训材料及辅导 资料, 以提升教师的行业声誉。

（4）构建基于真实工程造价咨询情境的 “项目化教室+BIM 造价工作室+实训基地” 教学资源平 
台。通过整合学校现有的造价教学资料库、工程图集库、造价案例库、造价软件库, 以及校外 造价实践基地等资源条件，对建设项目工程造价咨询工程进行实时模拟， BIM 建模与算量， 促使教学情境的真实化, 提高工程造价学生 “真题真做” 的动手操作能力, 在学校获得工程师 训练。

（5）建立并完善 “双导师” 联合指导毕业实习、毕业设计的机制。通过搭建 “双师型师资队 伍” , 通过 “双导师” 制模式, 建立校内专业教师与工程造价咨询行业高级工程师、造价工程 师联合指导工程造价专业毕业实习、毕业设计的培养新路径。

(6) 结合学校绩效工资改革, 完善师资队伍考核体系, 强化教育教学改革激励机制, 鼓励专业 教师到市内外高校、国际知名造价咨询企业开展专业教学改革调研, 积极申报各级各类教育教 学改革研究项目。

(7) 建立和完善反映工程造价专业发展状态的动态数据库, 全面掌握本专业发展真实状态, 分 年度评价专业的发展水平，为专业建设提供基本依据。

4. 3. 大数据模式下现代化教学方法改革路径

(1) 利用微课幕课建设平台, 开展网络辅助教学。利用精品课程、微课、幕课等课程网站, 在 网络上开辟教师教案、练习题库、实践教学、教学录像、电子课件等栏目, 创造一定的网络教 学环境, 学生可访问丰富的教学资源, 完成网上作业、实验、测验。提高教学效率, 将课堂教 学延伸到课外, 增加自主学习。

(2) 应用视频实验等现代教育技术开展实践教学。通过远程视频实验室, 学生可以在实验室观 看学校 10 公里范围内施工项目, 使工程造价专业学生近距离了解正在施工项目现场实际, 把 有形的工程实体转变为数字化空间, 以直观、形象和生动的形式引导学生自主学习, 解决学生 对施工工艺不熟悉的难题。

(3) 通过 BIM 造价管理沙盘实验, 推行参与式、讨论式教学方法。通过 BIM 造价管理沙盘实 验, 学生亲身体验工程项目管理环境, 应用所学理论开展项目管理决策、组织、协调、控制工 作, 促进教师和学生互动交流, 促进学生创造性思考问题, 培养学生对知识的 BIM 造价管理 综合应用能力和组织协调能力。

(4) 行业专家、能手走进实践教学。工程造价专业的工程造价编制、工程计量等课程实践性很 强, 软件升级速度快, 邀请行业专家、能手走进实验室为学生进行造价软件培训, 讲解最新编 制方法与技巧。在毕业实习环节，请建设单位、咨询单位和施工单位专家为学生讲解建设项目 管理知识、工程造价编制经验与技巧、大型项目施工管理技术等。

(5) 改革考试内容和形式, 注重学生 BIM 造价信息建模能力培养。建立课程考试试题库的同时, 增加了能够发挥学生主观能动性和开发创新能力的考题, 并结合学生参与课程设计和案例分析 时的表现, 对学生的创新能力进行测评。在施工组织学、建筑施工、工程造价编制等课程中增 加方案设计比赛、模拟招投标等课程设计考核方式，新的考试方法不仅调动学习积极性，同时 也拓展了他们的创造性思维。

(6) 探索创新人才培养方式。积极改进和完善造价管理模拟训练, 配备具有丰富实战经验的教 师指导学生模拟训练, 让学生在仿真建设项目管理环境中体会造价管理全过程; 完善并强化工 程造价的专业实习、毕业实习的组织和执行方式, 巩固课外专业实习基地, 保障学生能按教学 计划进入对口工程造价与工程咨询企事业单位实习和训练; 科学设置课程设计、毕业论文、工 程调研等创新实践环节实践教学方法, 配备有丰富教学和科研经验的教师指导学生收集整理文 献资料、设计研究方案、掌握研究手段和调研方法, 加强学生的多学科理论知识和技能的综合 运用能力训练。

\section{5. 小结}

本文根据大数据及 BIM 工程造价管理信息化背景下工程造价专业人才培养存在的问题, 结合 专业建设目标, 就交通土建院校工程造价专业人才培养模式架构、配套教研教改内容举措、完 善课程设置、适应 BIM 技术与工程造价管理信息化的现代化教学方法改革路径、探索创新人 
才培养方式、实践教学环节建设、BIM 实验实训基地建设等专业建设路径进行探讨, 并分析 工程造价专业人才预期效果。

\section{6. 致谢}

基金项目：重庆市教育科学规划课题（2014-GX-031); 重庆市研究生教育改革研究项目 (yjg153049)

\section{参考文献}

[1] 尹贻林, 白娟. 应用型工程造价专业人才培养模式的探索与实践--以天津理工大学为例 [J]. 中国工程科学, 2015,1[S1].

[2] 姜利妍, 冯钢. 工程造价专业实训课程 “二化结合” 教学模式的实践研究 [J]. 中国成人教 育, 2015,6.

[3] 徐秀维, 顾艳阳. 以工程造价专业为例论高职教育质量标准体系构建 $[\mathrm{J}]$. 教育与职业, 2014,6 .

[4] 严玲, 邓新位, 间金芹. 应用型本科工程造价专业双证书认证模式研究[J]. 高等工程教育研 究, 2014,5.

[5] 汪应洛, 王能民. 我国工程管理学科现状及发展[J]. 中国工程科学，2006, 3:11-17.

\section{Acknowledgement}

Fund project: chongqing education scientific planning project (2014 -GX -031); Graduate education reform project in chongqing (yjg153049).

\section{References}

[1] L.Y. Yin and J. Bai: Exploration and Practice of Talents Training Mode of Application Oriented Engineering Cost Specialty--Take Tianjin University of Technology as an Example [J]. Engineering Science, Vol. 17(2015) No. 1, p. 114-119.

[2] L.Y. Jiang and G. Feng: Practice and Research on "Combination of two" Teaching Mode of Engineering Cost Specialty Training Course [J]. China Adult Education, 2015, No. 6, p. 145-147.

[3] X.W. Xu and Y.Y. Gu: Taking the Engineering Cost Specialty as an Example, the Construction of the Quality Standard System of Higher Vocational Education [J]. Education and Vocation, Vol. 390(2014) No. 6, p. 37-38.

[4] L. Yan, X.W. Deng and J.Q. Yan: Research on double Certificate Authentication Mode of Engineering Cost Specialty in Application Oriented Undergraduate Course [J]. Research in Higher Education of Engineering, 2014, No. 5, p. 72-78.

[5] Y.L. Wang and N.M. Wang: Current Situation and Development of Engineering Management in China [J]. Engineering Sciences, 2006, No. 3, p.11-17. 